\title{
The Role of Indigenous Languages in Sustainable Development in Kenya
}

\author{
Emily Ayieta Ondondo \\ Department of Linguistics, Languages and Literature, School of Humanities and Social Sciences, Jaramogi Oginga Odinga University of \\ Science and Technology (JOOUST), Bondo, Kenya
}

Email address:

eondondo@gmail.com

To cite this article:

Emily Ayieta Ondondo. The Role of Indigenous Languages in Sustainable Development in Kenya. International Journal of Applied Linguistics and Translation. Vol. 6, No. 2, 2020, pp. 42-46. doi: 10.11648/j.jjalt.20200602.11

Received: March 13, 2020; Accepted: March 31, 2020; Published: April 14, 2020

\begin{abstract}
A developed nation is a knowledgeable nation in educational, social, political, economic and cultural spheres. For individuals to develop educationally, socially, politically, economically and culturally, they need to interact with government agencies that disseminate related policies. Effective interaction and communication of related policies occurs through language and effective communication is achieved through a language that the communicants understand best. Therefore, to achieve national development in all areas, in Kenya, indigenous languages become pertinent in effective communication of information related to national development goals. This is because leaders and stakeholders in these areas need to effectively communicate information pertaining to their goals to the people at the grassroots, majority of who use indigenous languages as their main and most times sole language of interaction. In addition, a number of development indices, such as, national cohesion, integration, unity, economic wellbeing and citizen participation are all linked to the use of indigenous languages that promote them. Therefore, indigenous languages seem significant in the overall development of a nation. However, these languages are least considered in the propagation of development issues, something which has been left for Kiswahili and English. Using a descriptive design, this study, therefore, provides rationale for suppressed use of indigenous languages in development issues, as well as justification for the overt use of these languages in development issues for sustainable development.
\end{abstract}

Keywords: Indigenous Languages, Sustainable Development, Effective Communication, Development Policies, Development Goals, National Cohesion

\section{Introduction}

Kenya is classified as a developing country [1]. This implies that sustainable development is yet to be achieved in Kenya. Although, Kenya's economy has continued to be the largest in the East African region and that Kenya is one of the most highly literate countries in sub-Saharan Africa, more than $60 \%$ of the Kenyan population lives below the poverty line [2]. This shows that Kenya is not a sustainably developed country. Another factor pointing at Kenya as lagging behind in attaining sustainable development is the Government of Kenya's four big priority areas of development thus: agricultural and food security, affordable housing, increased share of manufacturing and universal health coverage.

If Kenya is to achieve the big four priority agenda, support from the public is inevitable. To ensure robust public participation in achieving Kenya's sustainable development goals, key information pertaining any development issues in all areas of concern should be passed on to the public and the masses who participate in implementing and attaining them. All stakeholders in each sector, therefore, should endeavor to communicate the information to the people at all levels in their sectors.

Communication occurs through language and effective communication occurs through a language that the communicants understand best [3]. Given that language is the primary form through which messages (whether spoken or written) are expressed in communication, language is central and vital to effective communication [4]. This has the implication that the language used in any communication process would have an impact on effective communication of the messages.

Despite the fact that many of the people involved in executing the development agenda in Kenya predominantly 
use indigenous languages in their day today development activities, development issues in all sectors in Kenya are mostly communicated to these people through the use of English and/or Kiswahili and rarely through indigenous languages. Therefore, could it be that the reason as to why sustainable development has not been attained in Kenya is the language used in communicating information in development activities? The paper assesses the extent to which indigenous languages, which majority of the Kenyans speak, are used in communicating information regarding development issues in Kenya. It argues that the achievement of sustainable development in Kenya can only become possible through the use of indigenous languages as languages of communication in development issues and activities. The use of English and Kiswahili is a barrier to effective communication in development endeavors and makes the whole process foreign.

\section{Sustainable National Development}

Sustainable national development does not only

encompass a vibrant economy but also encompasses other indices such as unity, education, mass participation in government activities and maintaining law and order [5]. National development can be regarded as a situation whereby people harness the resources at their disposal in order to have meaningful life. This development ranges from growth in education (intellectual growth), politics, economy, science and technology [5] Sustainable development is development that considers providing the basic needs of the people and sustainability or conservation of resources. Sustainable national development, therefore, is the aggregate financial buoyancy as well as the education of and involvement of the citizenry in activities that will lead to the nourishing of a country's economy $[5,6]$.

Progress towards sustainable development needs changes at the local, national and international level [6]. In Kenya, sustainable development agenda, at the local level, encompasses many issues that are directly affecting indigenous peoples' lives. Education, poverty, food security, agriculture, health care, access to justice, technology, political stability, economic stability, social stability and climate change are some of the challenges that indigenous people have been and are currently facing in Kenya. The language, knowledge and know-how of indigenous people, deeply rooted in their relationship with nature and community, has proven to be efficient to respond to some of these challenges though not in entirety [7].

For Individuals at the local level, in Kenya, to develop educationally, socially, economically, politically and culturally, they need to interact with government agencies that disseminate ideas and policies through various media. This, however, needs to be done in the languages that these individuals best understand [8]. The use of indigenous languages in these interactions, therefore, becomes paramount. The use of indigenous languages will yield internal cohesion, integration, unity, economic wellbeing, mass participation in development activities, and educational growth. For $[6,9,10]$ argue that, for indigenous people, language and especially mother tongue is the main pillar through which stakeholders have to plan, instruct and evaluate development programmes in all sectors.

For sustainable development to be achieved, in Kenya, it is therefore, important that national development agenda starts recognizing indigenous peoples, their language and their knowledge as valuable allies in the fight against sustainable development challenges. This will empower indigenous people as well as enable them participate in the decision making process, making them active agents of change.

\section{Communication, Language and Sustainable Development}

Knowledge acquisition is facilitated through communication and communication occurs through language [11]. Understanding communication and how it works is important to human beings. This is because everyday activities and functions involve some form of direct or indirect communication. Regardless of the activity or function, the participants in a communication event communicate with and through other participants [12]. As a result, every participant's communication skills affect the effectiveness of any communication event $[13,14]$. It, therefore, seems reasonable to argue that one of the most inhibiting forces to the effectiveness of any communication event is a lack of effective communication (15) and that good communication skills are important to one's success as a participant in a communication event.

Human communication, however, is faced with a lot of problems and difficulties. Misinterpretations and misunderstandings arise more often than not. This is because whenever people try to communicate, something often seems to get in the way and they are not understood in the way they intended. Even when there is understanding it is often hard to get people to think or behave the way one would wish them to and this is largely dependent on the objective of the communication. For communication to be effective a message must be received (heard or read), understood, accepted and acted upon (change behavior or attitude). If this does not happen communication has failed and participants in a communication event get frustrated and resentful $[4,11]$.

Language is a distinctively human system of communication based on oral and written symbols. It is the vehicle through which people's culture is transmitted. It is an extremely important aspect of a community. It is an index of identity which serves as a repository of a people's culture, industry and exploits. It is language that differentiates the Homo sapiens from other animals [16, 17]. As a tool of communication among the members of a society, language is influenced by the very society where it functions. Moreover, being the most significant tool of communication, a particular language which is mastered only by some people has often been the determining factor in turning these people into a separate group as a people, a nation or a state $[18,19]$. As a 
system, language is, therefore, a general, abstract aspect and a sum of organization skills and principles that governs any concrete act of communication and acts as a means of communication.

Difference in language is the most obvious barrier to communication as two people speaking two different languages differ in their linguistic ability and can thus not communicate with each other $[4,12,20]$. The message that is to be communicated occurs as a thought in the mind of the sender. This thought has to be converted into an expressible form (code), that is, words and/or gestures [11]. Words constitute language, which is a code that can only be understood if both parties give the same meaning to the symbols that are used. Language is stored in the brain of human beings in form of lexical items and rules that determine how these items structure and function. Therefore, language, thought and culture are intertwined because thoughts and culture are expressed through language $[16,17]$. To produce real speech or writing, lexical items are retrieved from the brain and structured according to language specific rules and culture. In this way language, thought and culture have to work together as a system in the production of speech or writing.

Therefore, for communication to be effective there is need to use a language that both parties understand factoring in the linguistic ability of the communicants in the language, the amount of vocabulary they share and their culture [3]. In this case, in Kenya, the best language to be used for communicating development agenda to the people concerned should be their native languages as these are the languages that they know, have high linguistic abilities in, understand best, identify with and express their culture.

\section{Indigenous Languages, Knowledge and National Development}

The most effective engine of a people's culture is their mother tongue. Indigenous languages are treasures of our culture and self-identity [6]. In other words, it is the indicator of history and self-identification [10]. Mother tongue is an indispensable cultural legacy with which all forms of human interactions are carried out [21]. According to [9] it is the key to the heart of the people. If we lose the key, we lose the people. If we treasure the key and keep it safe, it will unlock the door to wealth or affluence. Therefore, the success of sustainable development projects depends on the participation of indigenous people at all stages, including design, planning, implementation and evaluation of plans [22]. The need to the participation of local people in development activities, in Kenya, makes the use of indigenous languages and knowledge indispensable.

Indigenous knowledge systems, rooted in indigenous languages, are the basis of decision making at the local level [23]. This is because such knowledge is the result of the efforts of local people to identify problems and find solutions to help innovation and to experiment them [23]. Local people develop new technologies at the local level and benefit from indigenous communication organizations for their dissemination [24]. The role of indigenous knowledge in collaborative activities for achieving development has expanded in recent years [6]. In some communities, indigenous knowledge is considered as a priceless national heritage that provides opportunities for social development programs and helps to identify, prioritize and organize local interests $[6,24]$. This implies that indigenous knowledge also has a big role to play in development issues. Indigenous languages are the carriers, transmitters and actualizers of indigenous knowledge.

The perspective of indigenous peoples is vital in identifying their development needs $[22,25]$. However, the conflict between indigenous knowledge and formal knowledge in development activities cannot be ignored and requires the merging of the two. This is because given the current state of the world, solutions to many development challenges need to be searched in the integration of indigenous knowledge and formal knowledge [26]. And also because due to the current development needs of Kenya's population and vulnerability of remaining natural resources, none of the two types of knowledge can alone meet the required development needs. Proper detection of indigenous development problems and effective communication with indigenous people can only be achieved effectively through the use of indigenous languages.

Indigenous languages can play a big role in national development. Indigenous languages can act as catalysts in educational development which is an important index of national development. Qualitative education in any nation is not a luxury, but an imperative to national development [6]. In order to achieve national cohesion and unity Kenya recognizes the importance of indigenous languages as articulated in the Constitution. It also recognises the importance of mother tongue education as articulated in the National Policy on Education that the language of instruction in lower primary school should be initially in the child's mother tongue or the language of the catchment area. Multilingual education is capable of eradicating illiteracy as it provides political awareness and socio-political stability. National unity depends largely on mutual understanding of each other's language and culture, including interests. Kenya should thus consider it to be in the interest of national unity that each person should be encouraged to learn other indigenous languages other than his/her own mother tongue. Unity means strength or power, and it is language that unifies people. Indigenous languages therefore confer power on a nation. Given that indigenous languages are the most important tools with which society is organized and that it is hardly possible to talk of national development without including the languages with which the people formulate their thoughts, ideas and needs, government's programmes and policies on development issues should reach the grassroots with the use of indigenous languages. 


\section{The State of Indigenous Languages in Kenya}

In Kenya, indigenous languages are the various native languages spoken in Kenya. These are languages that are aboriginal to the people. Currently, there are about 47 indigenous languages spoken in the country, making Kenya a multilingual and multi-cultural nation. None of these languages has official or national status, positions left for English and Kiswahili respectively. Indigenous languages are limited to the locality in which they are spoken and are recognized, if at all, only by members to which they are first languages.

Indigenous languages, in Kenya, are very diverse linguistically, unequal in size and status, and are at different stages or levels of development. The orthographies of many of them have not yet been designed or developed. This means that many of them are yet to be committed into writing and that literacy in many of these languages is very low. The contrary is the case for English and Kiswahili. There are fully developed orthographies for English and Kiswahili, languages that have also been committed into writing. Literacy in English and Kiswahili is also higher compared to that of indigenous languages.

Given the scenario above, indigenous languages have no substantive status in Kenya. They are marginalised and only function at the local level. Due to the prestige accorded to English, these languages are not widely used outside their locality. Some, especially those spoken by minority groups are not used at all outside the family setup due to negative attitudes towards these languages by their speakers. In this way, indigenous languages together with their rich indigenous knowledge, in Kenya, are endangered. All these constitute impediments to the development of indigenous languages and hindrances to their use in development activities in Kenya.

\section{Development of Indigenous Languages in Kenya}

Though Kenya is a plural society with a multiplicity of languages and dialects competing for recognition, optimal utilization of indigenous languages in national development would require the designing and development of orthographies in all these languages for literary use. When these languages are put into use, on equal status, none of them will be in competition for recognition with the other. Similarly, the many Kenyan indigenous languages that are becoming moribund and are on their way to extinction, as a result of lack of use, will be revitalised. Using indigenous languages, in this sense, will make them gain relevance and political domination. They will be the languages of trade and the negative attitude towards them will subside if not cease.

It is indisputable that the loss or death of some indigenous languages is an irretrievable loss of the peoples' collective wisdom. It is the loss of people's cultures, traditional occupations, medicine, technology and terminologies that are important in national development. This is because the richness of any nation, or any civilization, is a function of its language and culture. Therefore, the first step in achieving literacy in indigenous languages, in Kenya, for use in national development is language documentation, which is the panacea to language death. Therefore, the departments of Linguistics and Languages in our universities should work out best practices for the documentation of Kenyan indigenous languages. There is the need for government, NGOs, international bodies like UNESCO, UNICEF, the mass media and the speaker communities to fund language research so that our indigenous languages will serve as a veritable tool for national development.

However, the immediate and more effective mechanism of integrating the use of indigenous languages into national development is to incorporate a language interpretation service into redesigned work processes. In the beginning, the jargon may be a challenge in terms of equal and one to one translation from English and/or Kiswahili to the target indigenous languages. However, inventions, nativisations, borrowings and coinages are not farfetched. With time these can be developed into full blown jargons ingrained in the specific indigenous languages. This will in the long run not only alleviate illiteracy in these languages but also the illiteracy that comes with the use of English and/or Kiswahili in development activities where people in the rural areas are concerned. The interpreters should be people from the same community and having resided in the community for the same time as the majority of the community members to guard against the cultural difference barrier.

Similarly, this will provide an opportunity to help develop oral and written literacy in these languages both for the native and non-native speakers of these languages. This is an opportunity for Kenya as it will go further in enhancing the use of these languages in all spheres of national development, given that these languages are the engines driving community life, which embraces both social economic and development issues.

\section{Conclusion}

Indigenous languages are indispensable cultural legacies without which all forms of human interactions can be carried out. National development, that entails the development of individuals educationally, socially, politically, economically, and culturally, is achievable through interaction with government agencies that disseminate policies through various indigenous languages. Development indices such as internal cohesion, integration, unity, economic wellbeing and citizens' participation in governance need to be promoted through indigenous languages. Therefore, indigenous languages play a fundamental role in issues such as democracy, technology, agriculture, health, national cohesion and development as a whole. There are however some challenges in the optimum utilization of these mother tongues in national development. The major problems are orthographic inadequacy, the multiplicity of indigenous languages and 
language endangerment. Nonetheless, all is not grim. Indigenous languages can be developed for use in national development through designing of orthographies, robust language research, documentation and interpretation services. All these achieved through the joint efforts of the government, NGO's, international bodies, mass media and the native speakers of these languages.

\section{References}

[1] World Bank Group. (2018). Kenya Economic Update, April 2018, No. 17: Policy Options to Advance the Big 4. World Bank, Nairobi.

[2] Mohajan, H. K. (2013). Poverty and Economic Development of Kenya. International Journal of Information Technology and Business Management, 18 (1), 72-82.

[3] Ogechi, N. (2001). Publishing in Kiswahili and Indigenous Languages for Enhanced Adult Literacy in Kenya. Afrikanistische Arbeitspapiere 68 (2001)-Swahili Forum, 3, 185-199.

[4] Stanton, N. (2009). Mastering Communication. Palgrave: Macmillan. Technology Policy Studies Network. University Press.

[5] Adeniyi, H \& Bello, R. (2006). Nigerian Media, Indigenous Languages and Sustainable Development. In: Selected Proceedings of the 36th Annual Conference on African Linguistics. Olaoba F. Arasanyin \& Michael A. Pemberton (eds.), 155-160. Somerville, MA: Cascadilla Proceedings Project.

[6] Olaoye, A. A. (2013). The Role of Indigenous Languages in National Development: A Case Study of Nigerian Linguistic Situation. International Journal of Applied Linguistics \& English Literature, 2 (3), 29-34.

[7] Sultana, R., Noor, M. \& Zakaria A. K. M. (2018). Role of Indigenous Knowledge in Sustainable Development. International Journal of Development Research, 8 (2), 18902-18906.

[8] Elugbe, B. (2006). Documenting Endangered Nigerian Languages: Challenges and Constraints. In: proceedings of the National workshop on best practices to safeguard endangered Nigerian languages.

[9] Nwadike, E. (2004). The Role of Igbo in Enhancing National Unity. In Oyewole (ed.) Nigerian Languages for National Development and Unity. Ibadan: Longman Communication.

[10] Solanke, J. (2006). What Has Folklore Got to Do With It? Endangered Languages and the Electronic Age. In: Proceedings of the National Workshop on Best Practices to Safeguard Nigerian Languages. Abuja: UNESCO Publication.
[11] Ondondo, E. A. (2014). Effects of Communication Impairments on Knowledge Acquisition. Us-China Foreign Language, 24 (10), 805-813.

[12] Lunenburg, F. C. (2010). Communication: The Process, Barriers, And Improving Effectiveness. Schooling, 1 (1), 1-11.

[13] Brun, J. P. (2010). Missing Pieces: 7 Ways to Improve Employee Well-being and Organizational Effectiveness. New York: Palgrave Macmillan.

[14] Summers, D. C. (2010). Quality Management: Creating and Sustaining Organizational Effectiveness. Upper Saddle River: Prentice Hall.

[15] Lutgen-Sandvik, P. (2010). Destructive Organizational Communication: Processes, Consequences, and Constructive Ways of Organizing. New York: Routledge.

[16] Crystal, D. (2010). The Cambridge Encyclopedia of Language. Cambridge: Cambridge.

[17] Fromkin, V. R., \& Hyams, N. (2010). An Introduction to Language. Boston: Thomson-Henle.

[18] Fasold, R. (1992). The Sociolinguistics of Society. Oxford: Blackwell.

[19] Wardhaugh, R. (1992). An Introduction to Sociolinguistics. Oxford: Blackwell.

[20] Akmajian, A., Demers, R., Farmer, A., \& Harnish, R. (2010). Linguistics: An Introduction to Language and Communication. Cambridge, Mass: MIT Press.

[21] Alamu, O. (2017). Sustainable Development Goals in Nigeria: What Role (s) for Nigeria's Indigenous Languages? European Journal of Research and Reflection in Educational Sciences, 5 (4), 1-13.

[22] Olaoye, A. A. (2009). Language and the Re-branding Project in Nigeria. A Lead Paper Presented at the National Conference of the School of Languages, FCE. Obudu, Cross Rivers State.

[23] Bakare, O. B. (2000). Mother Tongue as a Medium of Instruction in the Years 2000 and Beyond; Implication for Nigerian Primary Education. In: Language, Literature and Linguistics in the 21st Century. Kaduna: NCCE Publication.

[24] Asade, B. K. R. (2000). Language, Literature and National Development. In Language, Literature and Linguistics in the 21st Century. Kaduna: NCCE Publication.

[25] Brokensha, D., Warren, D. M. \& Werner, O. (1980). Indigenous Knowledge Systems and Development. University Press of America, Lanham, MD.

[26] Safakish, M. (2015). The Role of Indigenous Knowledge in Sustainable Rural Economic Development. Journal of Applied Environmental and Biological, 5 (9), 285-289. 